\title{
ABO Hemolytic Disease of the Newborn
}

National Cancer Institute

\section{Source}

National Cancer Institute. ABO Hemolytic Disease of the Newborn. NCI Thesaurus. Code C106273.

A condition of the newborn characterized by the destruction of red blood cells initiated by the transmission of anti-A or anti-B antibodies from a mother to the child via the placenta against A or B antigens of the newborn's blood. 